\title{
Editorial: Before-After Control-Impact (BACl) Studies in the Ocean
}

\author{
Kerri D. Seger ${ }^{1 *}$, Renata Sousa-Lima ${ }^{2}$, Juan J. Schmitter-Soto ${ }^{3}$ and Edward R. Urban Jr. ${ }^{4}$ \\ ${ }^{1}$ Applied Ocean Sciences (AOS), Fairfax Station, VA, United States, ${ }^{2}$ Laboratory of Bioacoustics (LaB), Federal University do \\ Rio Grande do Norte, Natal, Brazil, ${ }^{3}$ El Colegio de la Frontera Sur (ECOSUR), Chetumal, Mexico, ${ }^{4}$ Scientific Committee on \\ Oceanic Research, Newark, NJ, United States
}

Keywords: BACl, ocean, sound, impacts, acoustics

Editorial on the Research Topic

Before-After Control-Impact (BACI) Studies in the Ocean

\section{INTRODUCTION TO BEFORE-AFTER CONTROL-IMPACT METHODOLOGIES}

The responses of marine organisms to changes in their environments can be studied using a variety of methods. Captive studies are highly controlled approaches that measure one or more parameters of interest in an enclosed area. Sample sizes are usually small, but experimental design and measurement methods are more controllable than in natural environments. However, captive experiments are not good models for the natural environment and cannot study the effects of largescale disturbances, human-driven or otherwise, on large marine organisms, populations of marine organisms, or ecosystems.

The Before-After Control-Impact (BACI) methodology (Green, 1979; Stewart-Oaten and Bence, 2001) is commonly used in terrestrial and limnological ecology studies; they are non-randomized methods that can employ a variety of statistical tests. BACI approaches include time and impact factors, with a control site and a comparably impacted site, both represented by data before and after the impact. The BACI approach makes it possible to account for any natural or preexisting differences between the sites, and thus to estimate the "true" effect of an impact variable between the control and the impacted site. "Before" can be either a "true" baseline for both sites, or just a comparatively unimpacted situation; likewise, "control" can refer to a group either fully or partially sheltered from the impact. Other approaches, such as studying only the present (post-impact) situation, or even comparing the past and present situation in a single site or group, are less powerful. These approaches cannot capture the variability due to differences in time elapsed or location vs. the variability caused by the impact (Christie et al., 2020).

BACI methods have been applied in a variety of ocean studies (e.g., Francini-Filho and Moura, 2008; Schmitter-Soto et al., 2018), but is not a well-known approach in the oceanography community. BACI is not a perfect methodology, as site choice and sampling rate need to be determined strategically (Smokorowki and Randall, 2017), but baseline studies before expected large-scale impacts lend themselves to the "before" or "control" portions of BACI experiments. Therefore, learning how to best implement BACI methodologies from other ecological fields and applying them to the ocean could provide a common language for understanding human impacts. The rationale for this Research Topic was to encourage wider use and standardization of BACI in the ocean environment. It provides examples of BACI and related approaches used to study acoustical and other impacts in the ocean, including six papers on the impacts of the COVID-19 pandemic on ocean sound, six other acoustical papers, and four papers on non-acoustical topics. 


\section{SUMMARY OF COVID-19 PAPERS}

The six papers that examined the impacts of the COVID-19 pandemic on ocean sound levels do not all strictly meet the criteria to be considered BACI studies as laid out in Smokorowki and Randall (2017), but they do provide important information for managers of sound-producing activities. Specifically, the COVID-19 pandemic provided more of a "reverse BACI," or "ICAB" (impact-control after-before) scenario with decreases in sound from shipping and other human activities during the early stages of the pandemic, relieving acoustical disturbance on ecosystems for a short time. In each of these articles, some reductions in ocean sound were observed, showing the magnitude of sound reductions possible from management measures to reduce ship traffic. The articles show that sound was significantly reduced during the early months of the pandemic (1) at a cold-water coral reef under a passenger ferry route between Norway and Sweden (De Clippele and Risch), (2) in a hightraffic area for cruise ships in Glacier Bay National Park in Alaska (Gabriele et al.), (3) in a sperm whale habitat in the Bahamas (Dunn et al.), (4) at two sites in the Baltic Sea (Basan et al.), (5) in the Monterey Bay National Marine Sanctuary (Ryan et al.), and (6) in the Halifax Harbor of Nova Scotia (Breeze et al.). Each paper used different methods to analyze changes, so the results are not directly comparable. Ambient sound in the ocean is thought to have increased $3 \mathrm{~dB}$ per decade (Hildebrand, 2009): the same magnitude as the sound decrease reported in some of these articles over a few months' time. Studies published in other journals have also found reductions in sound levels due to the pandemic (Thomson and Barclay, 2020; León-López et al., 2021; Pine et al., 2021).

\section{SUMMARY OF NON-COVID ACOUSTICAL PAPERS}

Six papers took a more straightforward BACI approach of measuring effects from an acoustical disturbance after a relatively less disturbed state. Varghese et al. found that multibeam echosounders in a beaked whale feeding area did not significantly alter their preferred foraging location. Durbach et al. found that minke whales altered their movement patterns and ceased calling during naval sonar training. Bouchet et al. performed a modeling study of the effects of naval sonar on tagged cetaceans to measure their responses and is the sole paper in this Research Topic to tackle the statistical implications of predicting sampling uncertainty in behavioral responses. Fernandez-Betelu et al. found that far-field impulsive sounds from pile driving do not force coastal bottlenose dolphins to vacate their habitat, but do affect their behavior, whereas Benhemma-Le Gall et al. determined that harbor porpoises were displaced during piledriving activities and from associated construction vessel activity for offshore wind farms. Burnham et al. found that vessel management efforts put in place to reduce stress on Southern Resident Killer Whales in the U.S. Pacific Northwest region decreased sound levels in frequency bands important to killer whale communication.

\section{SUMMARY OF NON-ACOUSTICAL PAPERS}

Four papers dealt with non-acoustical topics. Moland et al. examined the successful recovery of the structure and function of fish and lobster populations after 20 years of protection in the North Sea. Methratta reviewed methods to study the impact of offshore wind farms on various marine organisms by comparing BACI to alternative designs such as distance-stratified control-impact, before-after-gradient, and after-gradient (see also Benedetti-Cecchi, 2001 for a discussion of "beyond BACI methods"). Methratta is particularly useful for determining which impact study style may be more pertinent than others for oceanic research. Benoit and Fox-Kemper analyzed the impact of thermal effluents in Narragansett Bay, Rhode Island, demonstrating the effect of global warming over four decades. Finally, Stack et al. used a "before-after" scale of hours in a tropical environment in Australia, to show potentially detrimental behavioral changes in humpback whales due to ecotourism activities.

\section{CONCLUSION}

Currently, a standard set of guidelines does not exist for BACI studies in oceanography. Learning lessons from the ocean and other environments where BACI methodology has been applied (Underwood, 1994) will hopefully expedite formation of an accepted set of protocols in ocean science to accurately quantify disturbances and an ocean ecosystem's subsequent reaction. As climate change increases the rate of Arctic ice recession, warms the upper ocean, acidifies large regions of water, and expands oxygen minimum zones (IPCC, 2021), many of these impacts could be studied using BACI methods. We hope this Research Topic will lead to further development of BACI methods for ocean research to gain a more holistic understanding of anthropogenic effects on our planet. An important highlight of these studies is the importance of baseline measurements of important parameters before expected (e.g., windfarm construction) or unexpected (e.g., global pandemics and other natural disasters) environmental changes occur. Baseline studies are often the responsibility of governments because the results may not fit the usual requirements of experimental science. Such studies also should be funded by the industries that create environmental disturbances, and carried out by unbiased institutions and academia.

\section{AUTHOR CONTRIBUTIONS}

KS and EU developed the idea for the Research Focus, served as editors for some of the articles, and co-wrote this editorial. JS-S and RS-L served as editors for some of the articles and co-wrote this editorial. All authors contributed to the article and approved the submitted version. 


\section{REFERENCES}

Benedetti-Cecchi, L. (2001). Beyond BACI: optimization of environmental sampling designs through monitoring and simulation. Ecol. Appl. 11, 783-799. doi: 10.1890/1051-0761(2001)0110783:BBOOES2.0.CO;2

Christie, A. P., Abecasis, D., Adjeroud, M., Alonso, J. C., Amano, T., Anton, A., et al. (2020). Quantifying and addressing the prevalence and bias of study designs in the environmental and social sciences. Nat. Commun. 11:6377. doi: 10.1038/s41467-020-20142-y

Francini-Filho, R. B., and Moura, R. L. (2008). Evidence for spillover of reef fishes from a no-take marine reserve: an evaluation using the before-after control-impact (BACI) approach. Fish. Res. 93, 346-356. doi: 10.1016/j.fishres.2008.06.011

Green, R. H. (1979). Sampling Design and Statistical Methods for Environmental Biologists. New York, NY: John Wiley \& Sons.

Hildebrand, J. A. (2009). Anthropogenic and natural sources of ambient noise in the ocean. Mar. Ecol. Prog. Ser. 395, 5-20. doi: 10.3354/meps08353

IPCC (2021). “Summary for policymakers," in Climate Change 2021: The Physical Science Basis. Contribution of Working Group I to the Sixth Assessment Report of the Intergovernmental Panel on Climate Change, eds V. Masson-Delmotte, P. Zhai, A. Pirani, S. L. Connors, C. Péan, S. Berger, N. Caud, Y. Chen, L. Goldfarb, M. I. Gomis, M. Huang, K. Leitzell, E. Lonnoy, J. B. R. Matthews, T. K. Maycock, T. Waterfield, O. Yelekçi, R. Yu, and B. Zhou (Cambridge University Press), 41.

León-López, B., Romero-Vivas, E., and Viloria-Gomora, L. (2021). Reduction of roadway noise in a coastal city underwater soundscape during COVID-19 confinement. J. Acoust. Soc. Am. 149, 652-659. doi: 10.1121/10.0003354

Pine, M. K., Wilson, L., Jeffs, A. G., McWhinnie, L., Juanes, F., Scuderi, A., et al. (2021). A Gulf in lockdown: how an enforced ban on recreational vessels increased dolphin and fish communication ranges. Glob. Change Biol. 27, 4839-4848. doi: $10.1111 /$ gcb. 15798

Schmitter-Soto, J. J., Aguilar-Perera, A., Cruz-Martínez, A., Herrera-Pavón, R. L., Morales-Aranda, A. A., and Cobián-Rojas, D. (2018). Interdecadal trends in composition, density, size, and mean trophic level of fish species and guilds before and after coastal development in the Mexican Caribbean. Biodiv. Conserv. 27, 459-474. doi: 10.1007/s10531-017-1446-1

Smokorowki, K. E., and Randall, R. G. (2017). Cautions on using the Before-After-Control-Impact design in environmental effects monitoring programs. Facets 2, 212-232. doi: 10.1139/facets-201 6-0058

Stewart-Oaten, A., and Bence, J. R. (2001). Temporal and spatial variation in environmental impact assessment. Ecol. Monogr. 71, 305-339. doi: 10.1890/0012-9615(2001)0710305:TASVIE2.0.CO;2

Thomson, D. J. M., and Barclay, D. R. (2020). Real-time observations of the impact of COVID-19 on underwater noise. J. Acoust. Soc. Am. 147, 3390-3396. doi: $10.1121 / 10.0001271$

Underwood, A. J. (1994). On beyond BACI: sampling designs that might reliably detect environmental disturbances. Ecol. Appl. 4, 3-15. doi: 10.2307/19 42110

Conflict of Interest: The authors declare that the research was conducted in the absence of any commercial or financial relationships that could be construed as a potential conflict of interest.

Publisher's Note: All claims expressed in this article are solely those of the authors and do not necessarily represent those of their affiliated organizations, or those of the publisher, the editors and the reviewers. Any product that may be evaluated in this article, or claim that may be made by its manufacturer, is not guaranteed or endorsed by the publisher.

Copyright (c) 2021 Seger, Sousa-Lima, Schmitter-Soto and Urban. This is an openaccess article distributed under the terms of the Creative Commons Attribution License (CC BY). The use, distribution or reproduction in other forums is permitted, provided the original author(s) and the copyright owner(s) are credited and that the original publication in this journal is cited, in accordance with accepted academic practice. No use, distribution or reproduction is permitted which does not comply with these terms. 